\title{
Impact of Digital Marketing on End User Buying Performance Upon Retail Trade Business in UAE: A Case Study
}

\author{
Muhamed Faisal Panikkaveettil Muhamed and Shanavas Moosafintavida*
}

Azteca University, Mexico, North America

*Corresponding author: shanavas.musafi@gmail.com

\begin{abstract}
An attempt has been initiated to emphasize the influence of the rising trend of online shopping on numerous static shop retailers. Retailers encompass of a large segment of people and a bigger population is reliant on these retailers. Therefore, a study has been made to acknowledge the efficacy and impact of digital marketing in the buying behavior of consumers in the retail industry in UAE. The strength of digital marketing permits geophysical impediments to vanish making all buyers and business earth prospective consumers and dealers. Digital Marketing ability is to allow business to connect and create a business deal anywhere and anytime and lays down the influence on the mind of the consumer to buy the product. The arrival of e-stores with their appealing motivations and wide-ranging brands has smacked on their face the fear of ambiguity and dependence. This study also examines the different facets regarding the retail businesses and how are being influenced the various revival processes established to counter e-stores in the contest of existence due to digital marketing in UAE. Though the periodicity of the analysis is less, an active effort has been rendered to educate the situation along with definite proposals.
\end{abstract}

Keywords: E-stores, Fixed retailers, Window-shopping, Digital marketing, Online Marketing, ICT in Business, Information Seeking Behavior

Internet has unveiled the opportunity of tremendous digital marketing breaks for businesses. A business cannot just disclose their product and services online unless they utilize different channels of digital marketing ${ }^{[14],[15]}$. It gains clients for their business and can persuade them to boost their ROI. The rise of online networking has changed how organizations communicate with potential and existing customers. Different channels of digital Marketing like E-marketing, E commerce, social media, websites, and interactive marketing, support the corporates to reach their target customer ${ }^{[1],[5]}$. With the emergence of 
digital marketing, Physical shops are replaced by one digital devises in order to stop visiting the shops. Consumers are now accepting new products with good quality features with applause.

Purchasing products or services over the Internet, online shopping has attained immense popularity in recent mainly because people find it convenient and easy to shop from the comfort of their home or office and also eased from the trouble of moving from shop to shop in search of the good of choice. Online shopping (or e-tail from electronic retail or e-shopping) is a form of e-commerce which allows consumers to directly buy goods and services over the internet through a virtual shop. Some of the leading online stores currently in UAE are Souq, Awok, Noon, sharafdg, ubuy, namshi, openkart, gadget by etc. Retail is a process of selling goods and services to customers through multiple channels of distribution. Retail stores may be small or big, but they mostly operate in the same line as "purchasing to sale". Retail form of business is as old as civilization and is the most basic form of business. Types of Retail Stores are like Departmental Stores - A department store is a retail store which offers wide range of products to the end-users under one roof. In a department store, the consumers can get almost all the products they aspire to shop at one place only Discount Stores - Discount stores also offer a huge range of products to the end-users but at a discounted rate $\mathrm{e}^{[2],[3],[12]}$.

The discount stores generally offer a limited range and the quality in certain cases might be a little inferior as compared to the department stores. Supermarket - A retail store which generally sells food products and household items, properly placed and arranged in specific departments is called a supermarket. A supermarket is an advanced form of the small grocery stores and caters to the household needs of the consumer. Lulu Hypermarket, Carrefour, Geant Hypermarket, Saveco etc. are the budgeted stores run in the nearby locality to cater to daily needs of the consumers. They offer selected items and are not at all organized. Malls - Many retail stores operating at one place form a mall. A mall would consist of several retail outlets each selling their own merchandise but at a common platform. The Internet has many advantages over retail stores. Firstly, the choice, whereas the bookstore at the corner of the street or the nearby cloth store hardly offers 5000 references on its stalls or 20 designs of a garment of same size, Souk has got hundreds of thousands of varieties. Internet is full of online retailers offering 10 times or even 100 times more products than the average retailer can possibly dream of. For an e-commerce website, the costs of storing and referencing a product represent a small fraction of the cost as compared to the cost of storing and referencing a product for "physical" stores. From the customer satisfaction and availability of services, online shopping is creating a major impact upon the retail stores ${ }^{[4],[8],[14]}$.

With so many options available in the market, it becomes difficult for the consumers to become loyal and switching becomes easy, decide which social media platform the brand must use to expand its business. If the mass consumers are on Facebook, Snapchat, Twitter, Instagram, LinkedIn etc., it becomes mandatory for the brands to have their presence on these platforms if they want to be close to their prospects and a step ahead of their competitors, by interacting with their consumers buzz of their brand among them ${ }^{[6],[7],[17]}$.

\section{Review of literature}

Some of the research works, related to the "Impact of digital marketing on end user buying performance upon retail trade business in UAE: A Case Study" was studied to move this study and among them important are as follows-

The research work prepared by the Anthony D. Miyazakiand Ana Fernandez (2011) on 'Consumer 
perceptions of privacy and security risks for online shopping' and appeared in the Journal of Consumer Affairs. Another research work on "The impact of supercenters on traditional food retailers in four markets" conducted by the Kathleen Seiders, Constantine Simonides, Douglas J Tigertand appeared in International Journal of Retail \& Distribution Management. The study of Eunju Ko and Doris H Kincadeon "The impact of Quick Response Technologies on Retail Store Attributes" published in "International Journal of Retail \& Distribution Management" also considered as a vital source and helps in our present research design. Whereas regarding the impact on internet shopping the study by Soyeon Shim, Mary Ann Eastlick and Sherry Lotz prepared became important and published as "Assessing the impact of internet shopping on store shopping among mall shoppers and internet users" in the Journal of Shopping Center Research. Another work carried on 2014 entitled "The impact of online shopping experience on risk perception and online purchase intention: Does product category matter?" was valuable and carried by the Bo Dia, Sandra Forsythe and Wi-Suk kwon also valuable and appeared in Journal of "Electronic Commerce Research.

\section{Objectives of study}

The present research work entitled 'Impact of digital marketing on end user buying performance upon retail trade business in UAE: A Case Study"has been conducted with the following objectives and agenda (but not limited to) -

To study the effect on profitability of retail stores due to the advent of e-stores.

To learn about the basic of Digital Marketing and its seeking behaviors as well in brief.

To analyze the effect upon pricing patterns of retail stores in recent times.

- To analyze the change in business pattern to achieve customer satisfaction.

To recognize the effectiveness of digital marketing among consumers.

* To study the impact of digital marketing on consumer buying behavior.

- The limitations of the study also depicted in later section with possible suggestions in this work.

\section{Methodology of study}

The present study is interdisciplinary one entitled "Impact of digital marketing on end user buying performance upon retail trade business in UAE: A Case Study" and thus different methodologies have been adopted. Here research methodology comprises of the following -

Sources of data, methods adopted to collect such data,

* Sampling techniques,

- Statisticaltools for analysis,

* Data interpretation etc.

It is worthy to note that, different web-based sources also been used to reach the goal of the research work. Next section provides details in this regard. 


\section{Sources of Data}

* The data for the study have been collected from primary sources.

* Primary data have been collected through Direct Personal Interview method and through observation and collection of data through structured from 50 respondents

- Secondary data is collected from newspapers, journals, books, and magazines to develop the theory

Investigation through schedules at the various units for appropriate information.

\section{Universe of the Study}

The universe consists of all the retailers situated in UAE from which 50 respondents are selected at random for the purpose of the study.

\section{Sample Size and Sample Unit}

For the study, a sample of 50 respondents has been selected based on convenient sampling for the purpose of the research.

\section{Sampling Techniques}

For the study convenient sampling technique method has been applied based on suitability for the availability of information and which has a substantial share in the market to give more accurate picture of the impact of online shopping.

\section{Data Collection Techniques}

The data for the study has been collected through applying the following techniques: Direct Personal Interview and Investigation through schedules and Data Representation Tools The data collected are classified, tabulated, and represented through chart and bar diagram.

\section{Importance of the study}

This study is very much relevant to present times as this will make awareness about the impact of e-stores upon retail stores ${ }^{[9],[10],[16]}$. The sudden surge in online shopping and customers have adjusted to it to a greater extent which it a real cause of concern for the thousands of retailers who have a small shop offering a small variety of products which are their source of livelihood. This study wants to unravel the real scenario and investigate the threat that looms over the various small-scale retailers. In this study an attempt has been made so that retailers are aware of the upcoming that is expected to loom over their business soon so that they can appropriate arrangements to face such challenges. Dynamism stands the base of the current scenario andas a result of that anything that remains stagnant will be surpassed by others. It is time the retailers start thinking deep into this aspect and come up with better and advanced strategies. While increased visibility and access is good for your business, Internet marketing also benefits your customers $^{[1],[13]}$. Internet marketing is a to lead consumers honestly toward your product or service based 
on their criteria. Presenting them with the right, useful information at the correct time lets them make the choice to engage you, instead of you going after them.

* Consumers want relevant, engaging, and newsworthy content on demand. This means they expect to receive news about your industry as soon as it occurs, statistics about your industry, and other relevant information as it emerges. Internet marketing ensures consumers can find what they need to stay up-to date.

* The Internet offers consumers a greater variety and choice than they have ever had before. In this way, Internet marketing is a huge benefit to consumers on a global scale

* Consumers can find information about your business at any time of the day. This effectively gives them unlimited access to the brand, allowing to engage potential consumers i.e. digital marketing provides $24 / 7$ access.

* Internet marketing gives you a chance to reduce paper as more marketing campaigns shift to digital, Marketers can work from anywhere, cutting down on fossil fuel use, online shoppers don't need to drive to stores to find what they want.

\section{Periodicity of the study}

* The study has been conducted over a period of 3 months from January 2019 to March 2019.

For certain historic based data, it covers a period of two years from 2017 to 2019.

* However, the impact factor has been taken from data based on examination of retailers over a long period of time.

\section{PRESENTATION OF DATA, ANALYSIS, AND INTERPRETATION OF DATA}

Retail stores generally operated in the traditional lines of business except a few superstores that brought in certain modification in their business patterns, but the advent of online shopping in recent times has put an upon them because they had been losing on several ground. The study has been made on several grounds to understand the aspects of impact upon the business of various retailers that to some extent has led to a change in their strategies.

\section{Presentation of data}

Table: 1 Table showing the analysis of the various aspects of the impact of online shopping upon retail trade

Table 1: analysis of the various aspects of the impact of online shopping

\begin{tabular}{lll}
\hline List of Questions & Yes & No \\
\hline Has there been any decrease in average? Turnover in the past three years & 40 & 10 \\
Is there any decrease in profit margin? & 48 & 02 \\
Have you made any increase in discount rates offered to customer in recent times? & 37 & 13 \\
Do customers ask for discount before making purchases? & 45 & 05
\end{tabular}


Do you keep more variety of stock at your store now-a-days?

Do you provide after sale services of personalized nature to your customers?

Do you advertise about your enterprise?

Do you provide home delivery services to your customers?

$12 \quad 38$

Is there an increase in window shopping in recent times?

40

\section{Interpretation of the table}

The table highlights that there has been a decrease in turnover in most of the enterprises with a figure as high as $80 \%$. Most of the retailers has also agreed to a decrease in their profit margin in recent years as more discounts are been given by them to the customers in order to ensure a higher amount of sales. More customers are seen to as for discount in recent times. Retailers' now-a-days try to maintain a good variety of stock and provide various types of customer-oriented services in order to attain and retain customers. An alarming signal is the increase in window shopping which explains that prospective consumers do not turn into actual consumers. Here Fig. 1 showing the analysis of the various aspects of the impact of online shopping upon retail trade.

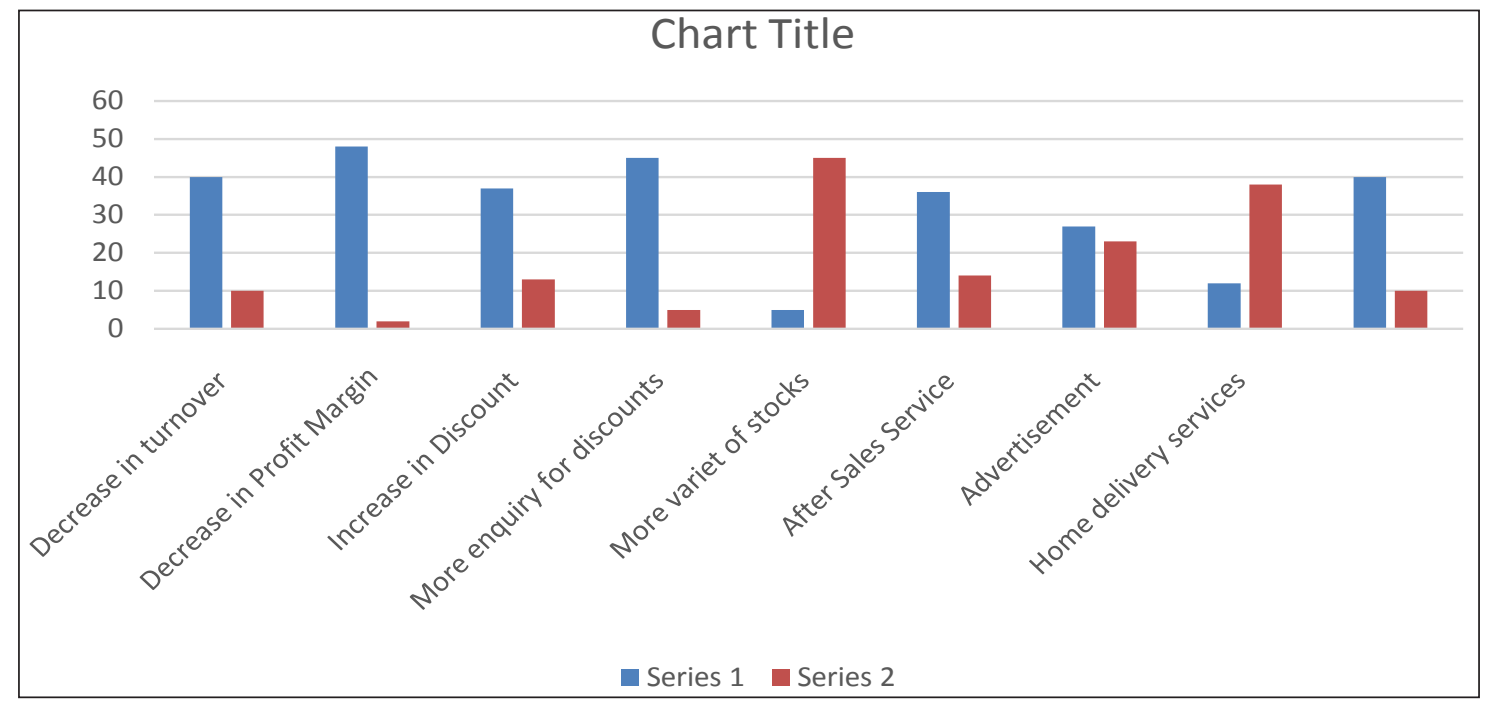

Fig. 1: the analysis of the various aspects of the impact of online shopping upon retail trade.

\section{Analysis and Interpretation of Retail trade}

Turnover: Retailers over a period of two years under study has noticed a considerable decline in their turnover as compared to years back. Some has reported if not decline but stagnancy in their growth which is a warning signal for the enterprise.

Profit margin: Online shops has brought in a price war in the market and the main sufferers of this price war are the retailers. In order to survive, most of these retailers too has made an attempt to lower their prices but considering their high cost of operation these retailers has to sacrifice on their margin. 
Discount: The retailers are at an alarming rate increasing their discounts in order to stand with the online stores who woes the customers with unbelievable discounts. Although the retailers cannot compete with the online stores in terms of discount, but it has to lower its prices to a relative extent to survive the market. Variety of stocks: Online stores maintain a wide variety of stocks and retailers fail in this context to theestores by a wide margin but most of the retailers as found by the survey has no inclination to compete with the online stores in this regard. The defeat is accepted. Retailers cannot maintain a large stock as that might have a negative impact of unsold stock at the end of the year which in turn might bring in huge loses to the concern.

Customer services: More and more retailers are now opting for customer services to build upon a loyalty. Repair and maintenance to installation and insurance, retailers are leaving no stones unturned to specialize in areas in which online shops fail. Retailers are now starting up with home delivery services in the same line of the online shops. Also, after sale services are provided with a smile.

Window shopping: There has been a trend in recent years for customers to browse the products in a physical store and buy it from an online store at a reduced price. Retailers now have more prospective customers than actual ones.

Advertisement: The retailers now-a-days are more involved in advertisement campaign than ever beforein order to increase their sales. Retailers leave no occasions to take advantage of the situation to advertise their firm.

The table 2 and the diagram highlight the fact about all these aspects, and it shows that there is a negative trend on all these aspects about the retailers.

Table 2: Analysis and Interpretation of internet marketing benefiting consumers

\begin{tabular}{llll}
\hline Question & Category & No. of Respondents & \% of respondents \\
\hline Gender & Male & 30 & 60 \\
& Female & 20 & 40 \\
& Total & $\mathbf{5 0}$ & $\mathbf{1 0 0}$ \\
\hline Age & Below 20 & 10 & 20 \\
& $21-30$ & 15 & 30 \\
& $31-40$ & 14 & 28 \\
& 41 above & 11 & 22 \\
Qualification & Total & $\mathbf{5 0}$ & $\mathbf{1 0 0}$ \\
& Undergraduate & 12 & 24 \\
& Graduate & 20 & 40 \\
& Postgraduate & 18 & 36 \\
& Total & $\mathbf{5 0}$ & $\mathbf{1 0 0}$ \\
\hline Occupation & Students & 8 & 16 \\
& Housewife & 11 & 22 \\
& Govt employees & 9 & 18 \\
& Businesspeople & 10 & 20 \\
& Private Employees & 12 & 24 \\
& Total & $\mathbf{5 0}$ & $\mathbf{1 0 0}$ \\
\hline
\end{tabular}




\begin{tabular}{llll}
\hline Monthly Income & Below 10000 & 8 & 16 \\
& $10001-20000$ & 12 & 24 \\
$20001-30000$ & 10 & 20 \\
& $30001-40000$ & 11 & 22 \\
& 40000 above & 9 & 18 \\
\cline { 2 - 3 } & Total & 50 & 100 \\
\hline
\end{tabular}

Awareness of DM

\section{FINDINGS, SUGGESTIONS AND CONCLUSIONS}

\section{Findings}

E-commerce is consistently taking up a larger proportion of consumer time and spending. There are several driving factors for consumers to shop online with price, convenience in shopping and wide range of available products being the primary. The major findings of the study are as follows:

Turnover and profit margin of the retailers has considerably decreased in the past few years.

Retail stores are now-a-days more engaged in services related to customer satisfaction.

* Although the retailers are not able to keep a wide variety in their stock, they attempt to keep the best of them to affect more sales.

* Customers are seen to make window shopping at an alarming higher rate to have a physical look at the product and buy that product online at a reduced rate.

* Retail stores are now starting up with home delivery services of their various products at the doorstep of their customers.

* The consumers become more comfortable with the experience of purchasing online with the convenience and product range become relatively more important as a deciding factor for shopping online.

\section{Suggestions}

Retailers must change their attitude towards the market. Today's is a consumer market and as a result the priority is the consumer satisfaction. The firm must be in the good books of the consumer. Better quality products, fair price and friendly after-sale services are the basic areas in which the business must concentrate to a remarkable extent. Additional services should be provided to the consumers to woe them and build upon a loyalty which in turn would ensure a stable sale in the years to come.

\section{Limitations of the study}

Despite all sincere efforts, the study is not foolproof in nature. It suffers from variety of limitations due to the following reasons: 
The study is limited to UAE cities only.

Besides that, the detailed study has been conducted taking on 50 retail stores based upon convenient sampling.

Data pertaining to the study has been collected for a period of only 2 years.

Time is also a limiting factor as the study is conducted in a noticeably short span of time.

\section{CONCLUSION}

This study has examined the different facets regarding the retail businesses and how are being influenced the various revival processes established to counter e-stores in the contest of existence due to digital marketing in UAE. The face of retail has changed. The advent of technology in recent period being the primary reason for it. Today, retailing means going into shopping centers, going online and going mobile. In all these, small retailers miss out somewhere. But the nearby store is always the most important concern for all reason and seasons. It needs to revive not just survive. The retail stores need to simply uplift its pattern of business and face the competitive world with a more positive outlook. E-stores and retail stores both must survive, none at the cost of the other. It's not just about the livelihood it gives to the thousands of people but also the convenience and the steadfastness of a fixed retail store.

\section{REFERENCES}

1. Aboelmaged, M. and Gebba, T.R. 2013. Mobile banking adoption: an examination of technology acceptance model and theory of planned behavior. International Journal of Business Research and Development, 2(1).

2. Ahmad, S.Z. and Khalid, K. 2017. The adoption of M-government services from the user's perspectives: Empirical evidence from the United Arab Emirates. International Journal of Information Management, 37(5): 367-379.

3. Al Athmay, A.A.A.R.A. 2015. Demographic factors as determinants of e-governance adoption: a field study in the United Arab Emirates (UAE). Transforming Government: People, Process and Policy, 9(2): $159-180$.

4. Al-Jenaibi, B. 2011. The use of social media in the United Arab Emirates: An initial study. European Journal of Social Sciences, 23(1): 84-97.

5. Arli, D., Tjiptono, F. and Porto, R. 2015. The impact of moral equity, relativism and attitude on individuals' digital piracy behaviour in a developing country. Marketing Intelligence \& Planning.

6. Bellman, S., Lohse, G.L. and Johnson, E.J. 1999. "Predictors of Online Buying Behavior", Communications of the ACM (Association for Computing Machinery), 42(12): 32-38.

7. Brindle, F. 2017. The impact of digital marketing disruption on the localization industry. Multilingual. March, 44-47.

8. Hsiao, T.C., Han, C., Qi, M. and Yu, X. 2016. The development and research of digital marketing in the contemporary society. In 2016 International Conference on Applied System Innovation (ICASI) (pp. 1-4). IEEE. 
9. Jasimuddin, S.M., Mishra, N. and A. Saif Almuraqab, N. 2017. Modelling the factors that influence the acceptance of digital technologies in e-government services in the UAE: a PLS-SEM Approach. Production Planning \& Control, 28(16): 1307-1317.

10. Kothari, C.R. 2010. Research Methodology Methods and Techniques, 2nd Revised Edition, New Age International (P)Ltd. Publishers.

11. Kumar, B. 2014. Impact of digital marketing and e-commerce on the real estate industry. International Journal of Research in Business Management, 7: 17-22.

12. Liang, T.P. and Huang, J.S. 1998. "An Empirical Study on Consumer Acceptance of Products in Electronic Markets: ATransaction Cost Model”, Decision Support Systems, 24: 29-43.

13. Richard Dobbs, Yougang Chen, Gordon Orr, James Manyika, Micheal Chui, Elsie Chang, China's e-tail revolution: Online shopping as a catalyst for growth, McKinsey \& Co, March 2013

14. Rowley, J. 2008. Understanding digital content marketing. Journal of Marketing Management, 24(56): 517-540.

15. Todor, R.D. 2016. Blending traditional and digital marketing. Bulletin of the Transilvania University of Brasov. Economic Sciences Series V., 9(1): 51.

16. Tripathi, P.C. 2007. Research Methodology in Social Sciences, 6th Revised and Enlarged Edition, Sultan Chand \& Sons.

17. Zhou, L., Dai, L. and Zhang, D. 2007. "Online Shopping Acceptance Model - A Critical Survey of Consumer Factors inOnline Shopping”, Journal of Electronic Commerce Research, 8(1): 41-62. 